\title{
МЕТОДОЛОГИЯ УПРАВЛЕНИЯ БЕСПИЛОТНЫМ ЛЕТАТЕЛЬНЫМ АППАРАТОМ
}

\section{UNMANNED AIRCRAFT CONTROL METHODOLOGY}

\section{T. Keribayeva}

Summary. The use of unmanned aerial vehicles is growing all the time, both in number and in scope. Therefore, the quality of control of these devices should also improve. This article discusses the control of an unmanned aerial vehicle based on the description of motion by differential equations, which are described by uncertainty controls. The use of this method will improve the stability of the program task execution.

Keywords: unmanned aerial vehicle, control system, differential equation.

\section{Введение}

развитием электроники и уменьшением ее веса стали широко применятся беспилотные летательные аппараты. Изначально их применяли для военных целей, но удешевление этой техники привело к использованию беспилотных летательных аппаратов в самых различных областях, таких как картография [1], кадастр [2], строительство и проектирование [3], нефтегазовая отрасль и энергетика $[4,5]$, лесное хозяйство и экологический надзор [6, 7], сельское хозяйство [8].

На сегодняшний день по данным UVS International (ведущей международной ассоциации беспилотных систем) беспилотные летательные аппараты производят в 52 странах мира [9].

Основной особенностью интеллектуальной системы навигации и управления современными беспилотными летательными аппаратами является объективная необходимость формирования, и реализации решений при минимальном участи персонала соответствующего беспилотного авиационного комплекса [10]. Качество выполнения многих заданий беспилотными летательными аппаратами зависит от точности управления [11].

И эффективность, и скорость выполнения поставленных перед БПЛА задач значительно возрастает, поэтому проблема управления БПЛА на сегодняшний день является актуальной.

\author{
Керибаева Талшын Бакытжанкызы \\ Докторант, Академия гражданской авиации, \\ Республика Казахстан, г. Алматы \\ talshyn.keribayeva@gmail.com
}

Аннотация. Применение беспилотных летательных аппаратов все время растет как по числу, так и по сферам применения. Поэтому качество управления этими аппаратами тоже должно расти. В настоящей статье рассматривается управление беспилотным летательным аппаратом на основе описания движения дифференциальными уравнениями, которые описывают управление неопределенности. Применение этого метода улучшит устойчивость выполнения программного задания.

Ключевые слова: беспилотный летательный аппарат, система управление, дифференциальное уравнение.

Процесс постоянного совершенствования авиационных вооружений базируется, в том числе, на самых современных достижениях в области информационных технологий [12].

Для эффективного выполнения беспилотным летательным аппаратом поставленных задач предусматриваются различные программные траектории его движения. В практических приложениях каждый БПЛА заранее программируется на полет по конкретной траектории. При этом учитывать изменения внешней среды и состояния БПЛА достаточно сложно, так как предварительная информация отсутствует. Поэтому вместо директивных систем управления БПЛА целесообразно использовать более сложные адаптивные системы, которые в меньшей степени, но все же требуют наличия априорной информации о состоянии БПЛА и среде его функционирования. Таким образом, при управлении БПЛА актуальной задачей является синтез системы управления.

\section{Математическая модель $\triangle$ Вижения БП АА}

Разработка подхода к управлению БПЛА предполагает решение целого ряда задач, одна из которых может быть решена с помощью адаптивного самоорганизующегося регулятора или регулятора с эталонной моделью. Однако в последнем случае необходимо иметь математическую модель движения БПЛА. Для этого на БПЛА следует установить дополнительные прецизионные дат- 
чики, на основе информации с которых осуществляется адаптивная подстройка в алгоритмах управления.

Математической задачи управления в условиях неопределенности БПЛА в текущий момент времени $\mathrm{t}$ задается фазовым вектором $x(t)=\left(x_{1}(t), \ldots, x_{n}(t)\right)$. Компонентами вектора $x(t)$ являются, в частности, геометрические координаты БПЛА и составляющие его вектора скорости. Полагаем, что изменение во времени фазового вектора удовлетворяет дифференциальному уравнению вида

$$
x(t)=f(t, x(t), u(t), v(t)),\left(t \geq t_{0}\right) .
$$

Здесь $u(t)=\left(u_{1}(t), \ldots, u_{p}(t)\right)$ - вектор управляющих воздействий. Его компоненты характеризуются различным движением и режимом работы двигателей в момент времени $t$.

$v(t)=v_{1}(t), \ldots, v_{q}(t)$ - вектор внешних возмущений. Этот вектор характеризует, например, силу и направление ветра.

\section{Функции времени}

$$
u(.)=\left(u(t), t \geq t_{0}\right) \text { и } v(.)=\left(v(t), t \geq t_{0}\right)
$$

будем называть в дальнейшем управлением и помехой соответственно.

Решение $x()=.\left(x(t), t \geq t_{0}\right)$ уравнение (1) будем называть движением управляемой системы. Предполагается, что допустимые управления и помехи удовлетворяют ограничениям

$$
u(t) \in P, v(t) \epsilon Q\left(t \geq t_{0}\right)
$$

где $\mathrm{P}$ и $\mathrm{Q}$ - множества в $R^{p}$ и $R^{q}$ соответственно, заданные физическими условиями задачи. Функция $f: R \times R^{n} \times P \times Q \rightarrow R^{n}$ в правой части уравнения (1) определена физическими законами, которым подчинено движение самолета. Предполагается, что имеет место достаточно хорошее соответствие математической модели реальному процессу [14].

Автоматическое управление посадкой включается в момент $t=t_{0}=0$, когда БПЛА находится в определенном районе, которому отвечает область $X_{0}$ фазового пространства $R^{n}$. В обсуждаемой задаче требуется обеспечить приведение БЛА к началу посадочной полосы со скоростью, величина и направление которой лежат в допустимых пределах. При это должны выполняться также некоторые условия безопасности полета. Примем, что эти требования можно формализовать в виде условий

$$
x(\tau) \epsilon M, x(t) \in N \text { при } 0 \leq t \leq \tau .
$$

Здесь $M-$ совокупность фазовых состояний, допустимых в момент посадки; $N$ - множество в фазовом пространстве $R^{n}$, отвечающее техническим условиям безопасности; $\tau=\tau(x())-$. момент посадки, т.е. момент времени, когда для движения $x()=.(x(t)), t \geq 0)$ впервые выполняется условие $x(t) \in M[15]$.

Отметим, что задача об автоматической посадке самолета рассматривается в условиях неопределенности, которая состоит здесь в том, что нельзя заранее предугадать, какая помеха реализуется в процессе движения. В такой ситуации важно различать два способа управления - программный и по принципу обратной связи. При первом способе управление $u()=.\left(u(t), t \geq t_{0}\right)$ выбирается в начальный момент $t_{0}$ как фиксированная функция времени, определенная на всем последующем промежутке времени; следует сразу признать, что рассматриваемую задачу нельзя решить в классе программных управлений. При втором способе управление формируется в процессе движения в зависимости от поступающей информации.

Предположим, что в процессе движения можно измерять какую-либо часть компонент фазового вектора $\chi(t)$, например первые $\mathrm{m}$ компонент $\left(x_{1}(t), \ldots, x_{m}(t)\right)=x^{[m]}(t)$. Предполагаем, что управления движением $u(t)$ назначается в зависимости от поступающей информации $x^{[m]}(t)$. В математической модели этому условию может отвечать формирование управления по закону $u(t)=U\left(x^{[m]}(t)\right)\left(t \geq t_{0}\right)$, где $U: x^{[m]} \rightarrow U\left(x^{[m]}\right)$ - некоторая функция, принимающая значения в множестве Р. В дальнейшем способ формирования управлений будет называть стратегией. В данном случае стратегия задается функцией U [15].

Итак, математическая задача управления будет стоять здесь в построении функции (стратегии) $U^{0}$, которая гарантирует выполнение следующего условия: (экстремальных ситуациях) $v()=.(v(t), t \geq 0)$ и начальная точка $x_{0}=x(0)$ из области $X_{0}$ для движения $x()=.(x(t), t \geq 0)$ управляемой системы

$$
x(t)=f\left(t, x(t), U^{0}\left(x^{[m]}(t)\right), c(t)\right)
$$

Должны быть выполнены условия (3).

Пусть $æ\left(X_{0}, U\right)-$ множество движений

$$
\begin{aligned}
& x(.)=(x(t), t \geq 0) \text { системы } \\
& x(t)=f\left(t, x(t), U\left(x^{[m]}(t)\right),\right. \\
& x(0)=x_{0} \in X_{0}, t \geq 0
\end{aligned}
$$






Рис. 1. Система управления обратной связью

Которое получается при переборе всех начальных точек $x_{0} \in X_{0}$ и всех допустимых помех $v()=.(v(t) \in Q, t \geq 0)$.Обозначим через М совокупность всех непрерывных функций $x()=.(x(t), t \geq 0)$, для каждой из которых выполнены два условия: 1) существует момент времени $\tau=\tau(x()$.$) , когда впервые x(t) \in M ; 2)$ выполняются включения $x(t) \epsilon N$ при $0 \leq t \leq \tau(x()$.$) .$ Используя введенные обозначения, приходим к следующей формулировке обсуждаемой задачи. В классе допустимых стратегий требуется определить стратегию $U^{0}$ правильно для этого $\left(X_{0}, U^{0}\right) \subset \mathcal{M}[15]$.

В задачах, где управление формируется по принципу обратной связи.
Регулятор $U$ в соответствии законом управления $U$ вырабатывает воздействие $u=u[t]$, которое и подается на систему $\sum$ в момент времени $t$ (Рис. 1).

\section{Зак^ючение}

В этой статье мы рассказали о воздействии на окружающую среду и эффективности применения беспилотных летательных аппаратов. Также рассмотрена автоматизация системы управления путем определения неопределенности в полете. Управление формируется по принципу обратной связи. Внедрение системы управления полетом значительно улучшит управляемость аппаратом и сделает его более надежным.

\section{ЛИТЕРАТУРА}

1. Гаврилова Л.А., Костеша В.А., Юнусов А.Г. Опыт использования материалов с беспилотных летательных аппаратов для создания картографической основы ГИС автомобильных дорог// Известия высших учебных заведений. Геодезия и аэрофотосъемка. 2019. Т. 63. № 4. С. 446-454.

2. Розенберг И.Н., Шайтура С.В., Макаров С.О., Зюкин Д.А., Белю Л.П., Илларионова Е.А. Кадастр недвижимости и мониторинг земель - Бургас, 2020.

3. Михеева А.А., Ялтыхов В.В., Парадня П.Ф. Аэросъемка с беспилотного летательного аппарата // Вестник Полоцкого государственного университета. Серия Ғ. Строительство. Прикладные науки. 2018. № 16. С. 135-142.

4. Мамедов И.Э. Вопросы использования беспилотных летательных аппаратов для обнаружения нефтяных пятен в прибрежной части морской акватории // Проблемы региональной экологии. 2019. № 4. С. 88-91.

5. Беляев П.В., Головский А.П., Садаев Д.С. Перспективы применения беспилотных летательных аппаратов при контроле и диагностике объектов энергетики// Динамика систем, механизмов и машин. 2019. Т. 7. № 2. С. 18-24.

6. Горелова Д.А., Горелова М.А. Преимущества использования беспилотных летательных аппаратов по сравнению с аэрокосмическим мониторингом в лесном хозяйстве // Студенческий вестник. 2020. № 11-3 (109). С. $28-31$.

7. Мусина Г.А., Ожигин Д.С., Ожигина С.Б. Экологический мониторинг на основе снимков, полученных с помощью беспилотных летательных аппаратов // Интерэкспо Гео-Сибирь. 2019. Т. 4. № 2. С. 196-204.

8. Шевченко А.В., Мигачев А.Н. Обзор состояния мирового рынка беспилотных летательных аппаратов и их применения в сельском хозяйстве //Робототехника и техническая кибернетика. 2019. Т. 7. № 3. С. 183-195.

9. Зинченко 0.Н. Беспилотные летательные аппараты: применение в целях аэрофотосъемки для картографирования (часть 1) -М.: Ракус — 2011

10. Тутубалин П.И., Кирпичников А.П. Структурно-функциональная модель бортовой экспертной системы управления перспективного беспилотного летательного аппарата // Вестник технологического университета- 2017 г. - Т. 20, № 20

11. Павлушенко М.И., Евстафьев Г.М., Макаренко И.К. Беспилотные летательные аппараты: история, применение, угроза распространения и перспективы развития- М.: Права человека, 2005.- 612 с. 
12. Краснильщикова М.Н., Себрякова Г.Г. Современные информационные технологии в задачах навигации и наведения беспилотных маневренных летательных аппаратов - М.: ФИЗМАТЛИТ,2009-556 c.ISBN978-5-9221-1168-3.

13. Тутубалин П.И., Кирпичников А.П. Структурно-функциональная модель бортовой экспертной системы управления перспективного беспилотного летательного аппарата // Вестник технологического университета. 2017. Т. 20, № 20

14. Субботин А.И., Ченцов А.Г. Оптимизация гарантии в задачах управления — «Наука», Москва-1981-с.9.

15. Никифоров В.0., Слита 0.В., Ушаков А.В. Интеллектуальное управление в условиях неопределенности. Учебное пособие — Санкт-Петербург - 2011-с.14

( Керибаева Талшын Бакытжанкызы ( talshyn.keribayeva@gmail.com ).

Журнал «Современная наука: актуальные проблемы теории и практики»



